\title{
Tecnologias da Informação e Comunicação no Contexto da Formação, Inicial e a Distância, de Professores de História
}

\author{
Márcia Maria Dias \\ Eucidio Arruda Pimenta
}

\section{RESUMO}

Este artigo tem como proposta analisar criticamente a incorporação das Tecnologias Digitais de Informação e Comunicação (TDIC) no contexto de formação inicial do docente de História, bem como refletir sobre a apropriação dessas tecnologias, para além de seu modo instrumental, na prática pedagógica dos professores de História da educação básica. Para tanto, parte-se do pressuposto de que o uso de tais tecnologias na prática docente deve ser fomentado pelo emprego delas no processo de formação dos professores, levando-se em consideração as influências e marcas que as práticas pedagógicas e didáticas da educação superior imprimem na formação docente inicial, e, consequentemente, nas ações desses futuros professores. Por fim, conclui-se que a formação do professor envolve uma formação crítica e propositiva no que tange as TDIC no intuito de compreender e usufruir de seus recursos em todos os aspectos sociais e não somente emaranhar-se nos encantamentos tecnológicos, imbuídos de diversas intencionalidades políticas.

Palavras-chave: Formação de professores de História. Tecnologias na Educação. Prática docente.

\section{INTRODUÇÃO}

Por muito tempo, a escola representou o único eixo de obtenção de informação e conhecimento para a maioria das pessoas. Nas perspectivas educacionais mais antigas, os alunos deviam buscar nas escolas o conhecimento transmitido pelo professor, então representante máximo do saber. A estrutura organizacional das instituições educacionais e, principalmente, as características comuns do corpo discente colaboravam para a calmaria tão peculiar ao ambiente escolar predominante nos moldes da educação tradicionalista.

Essa realidade mudou, pois a sociedade contemporânea tem vivenciado inúmeras e complexas transformações sociais de forma muito acelerada, desde as

Licenciada em História pela PUCMG; licenciada em Pedagogia pela FETREMIS; especialista em Docência do Ensino Superior pela FETREMIS e mestranda do PROMESTRE - Mestrado Profissional em Educação e Docência UFU. Contato: marcyamagaly@ hotmail.com

Doutor em

Educação,

professor do

Programa de

Pós-Graduação:

Mestrado

Profissional

de Educação e

Docência, linha de

pesquisa Educação,

Tecnologia e

Sociedade/UFU. 
últimas décadas do século passado. Conforme Giddens (1991, p.15), as transformações que permeiam a denominada modernidade são mais intensas que em outras épocas, tanto em extensionalidades, ao estabelecer formas de interconexão social, quanto em intencionalidades, ao alterar aspectos íntimos da existência cotidiana.

Nesse viés, acrescenta Arruda que,

as transformações tecnológicas vividas pelos sujeitos na contemporaneidade representam não só introdução de equipamentos e "técnicas" na sociedade, mas, principalmente, mudanças de ordens sociais, culturais, de trabalho e educacionais. (ARRUDA, 2011, p.13).

Portanto, os reflexos e impactos dessas mudanças, oriundas dos avanços da tecnologia, são perceptíveis em várias instâncias sociais, inclusive, na escola. Por tecnologia podemos compreender que se trata da capacidade de construir o mundo, possibilitando competências para a apropriação de recursos, sejam eles humanos, produzidos ou naturais. De acordo com Vieira Pinto (2005, p. 221), há ainda distinção entre técnica e tecnologia. Segundo o autor, técnica é um produto da percepção humana, ato produtivo materializado em instrumentos e máquinas, e tecnologia consiste na teoria epistemológica da técnica.

As tecnologias suscitam vários diálogos com a educação e com as práticas pedagógicas, ao provocarem alterações na forma de ensinar e aprender. Nas vivências cotidianas, professores e alunos interagem constantemente com as tecnologias digitais e isso remete a percebê-las na prática docente. Segundo Gatti (2010, p. 13), a educação "envolve a interação complexa de todos os fatores implicados na existência humana". Portanto, corroborando-se com Kenski (2005, p. 72), que afirma que é complicado limitar o processo de ensino e aprendizagem ao espaço físico da sala de aula.

As transformações advindas das tecnologias digitais são facilmente visíveis na sociedade, portanto, é objeto desta pesquisa analisar a incorporação, ou não, das tecnologias digitais na formação inicial, presencial e a distância, do docente de História. De acordo com

Arruda, entende-se que:

As chamadas tecnologias de informação e comunicação envolvem tipos distintos de tecnologia, utilizadas para a produção e transmissão de 
informações, bem como criar mecanismos mediadores de interação e comunicação entre homens ou máquinas e homens, além de sistemas de controle a automação dos processos de criação, transmissão e recepção de informação, bem como dos mecanismos de comunicação. (ARRUDA, 2013, p.3).

Nessa perspectiva, nota-se que as tecnologias digitais são usadas em vários espaços de vivências sociais, por alunos e professores. Esses usos sociais são apropriados por professores em suas práticas escolares? De que formas são contempladas e problematizadas na formação inicial do docente de História, haja vista que promovem mudanças consideráveis em vários âmbitos das relações sociais? Como as políticas públicas educacionais têm incentivado e oportunizado as interações com as tecnologias digitais de comunicação e informação? A partir desses questionamentos, torna-se pertinente analisar como têm sido incorporadas as abordagens problematizadoras sobre as tecnologias digitais na formação do professor de História.

As tecnologias digitais possibilitam alterações na vida de toda a sociedade, isso repercute na sala de aula e provoca a necessidade de compreender como são abordados criticamente os novos saberes e as novas linguagens dessas tecnologias.

É perceptível certo descompasso entre a prática ainda fundamentada no tradicionalismo pedagógico e a dinâmica tecnológica para além da sala de aula. Conforme Alonso (2008, p. 758), o fato de ter tecnologias tão sofisticadas no ambiente escolar não garante rupturas e mudanças nas práticas pedagógicas, principalmente, porque a inserção das tecnologias na dinâmica escolar requer alteração metodológica da própria prática pedagógica, trata-se de lógicas distintas, o que pode gerar até certo mal-estar pedagógico.

Segundo Tavares e Gomes (2014, p. 425), numa perspectiva crítica e dialógica, as tecnologias podem colaborar com a formação de pessoas mais autônomas e capazes de se gerirem socialmente. Nesse caso, o professor tem participação fundamental como mediador do processo.

Portanto, o objetivo geral desta pesquisa é analisar e problematizar a incorporação, ou não, das tecnologias digitais de informação e comunicação na formação presencial e a distância do professor de História. Para tanto, buscar-se-á identificar e compreender como se dão os processos de incorporação de TDIC na formação presencial e a distância do professor de História, além de compreender as relações que se estabelecem entre as TDIC e a licenciatura em História e apontar 
propostas para redefinição da incorporação das tecnologias de informação e comunicação na formação presencial e a distância do professor de História.

Espera-se provocar reflexões críticas e encaminhamentos, que contribuam com a formação do professor de História, pautadas no fato de que esse professor é essencial na formação social do educando.

\section{DESENVOLVIMENTO}

É indiscutível o impacto provocado pelas tecnologias digitais nas várias dimensões que integram na sociedade.

Assim, Castells (1999) apresenta o paradigma tecnológico sob o qual se organiza novas formas de desenvolvimento que confere ao capitalismo outras facetas por meio de redes interligadas. Portanto, instiga a sociedade no sentido de não negligenciar as transformações decorrentes das tecnologias digitais no panorama social da humanidade, pois ocorrem em um fluxo e em uma troca quase instantâneos de informação, capital e comunicação cultural.

Nesse viés, Lévy (1998) dialoga com Castells, ao abordar a sociedade em rede no que denominou por ciberespaço, ou seja, espaço de comunicação aberta mediada por computadores, concretizada na virtualização e que contribui para a formação das inteligências coletivas, redimensionando conceitos e concepções, pois:

A mediação digital remodela certas atividades cognitivas fundamentais que envolvem a linguagem, a sensibilidade, o conhecimento e a imaginação inventiva. A escrita, a leitura, a escuta, o jogo e a composição musical, a visão e a elaboração das imagens, a concepção, a perícia, o ensino e o aprendizado, reestruturados por dispositivos técnicos inéditos, estão ingressando em novas configurações sociais. (LÉVY, 1998, p.17).

Portanto, os autores discorrem sobre as mudanças provocadas na sociedade em virtude do impacto gerado pelas tecnologias digitais, reafirmando o que Castells vai definir como Sociedade da Informação.

Segundo Coll e Monereo (2010, p. 22-24), alguns aspectos delineiam a Sociedade da Informação (SI), tais como a complexidade, a interdependência e a imprevisibilidade nas quais se fundam as ações e relações humanas. Nessa linha, inclui a informação e o excesso de informação, aspectos elementares da SI, embora não haja garantia de informação qualitativa das pessoas, pois, para isso, presidem condições necessárias para filtrar e selecionar as informações.

Outro aspecto definidor dessa sociedade consiste na velocidade dos processos, 
ou seja, o intervalo de tempo entre a divulgação da informação, a sua caducidade e renovação é muito curto e não se restringe apenas à esfera informacional, mas se estende para outras composições sociais.

Essa rapidez pode implicar em superficialidade, na medida em que dificulta os processos de imersão e reflexão sobre as informações. Nesse sentido, Coll e Monereo corroboram que,

\begin{abstract}
Hoje, estamos obrigados a pensar mais rápido, mais do que a pensar melhor. A rapidez dos processos e transformações próprios da SI, juntamente com os fenômenos de excesso, obsolescência e renovação contínuos da informação, assim como a multiplicidade e heterogeneidade das fontes de informação, podem levar facilmente à diminuição e dispersão da atenção, [a] uma cultura de 'mosaico', carente de profundidade, à falta de estruturação, à superficialidade, à padronização das mensagens, à informação como espetáculo, etc. (COLL; MONEREO, 2010, p.23).
\end{abstract}

Diante dessas considerações, exige-se maior domínio e criticidade para desvencilhar-se pelas múltiplas linguagens tecnológicas de maneira mais reflexiva.

A preeminência da cultura da imagem e do espetáculo também contribuem para elucidar os complexos contornos da SI, pois, ao priorizar as inferências multisensoriais, a narrativa, a dinamicidade, as emoções em detrimento das racionalidades e o próprio sensacionalismo, criam-se novas possibilidades de conceber o pensamento, podendo-se alterar até as formas de sentir e agir. Como acrescenta Dantas,

Estão adquirindo um signo de pertencimento a uma específica (sub)cultura, a um bem definido estrato social, a um grupo de pessoas, homens e mulheres, que frequentam certos lugares, possuem determinados hábitos, identificam se umas às outras conforme estão vestidas, conforme falam ou gesticulam, conforme gastam o próprio dinheiro, conforme dispõe dos tempos de trabalho e de lazer. Conforme as músicas que escutam ou os móveis que exibem em casa. (DANTAS, 2014, p. 91).

Dessa forma, a cultura da imagem e do espetáculo prima por características que imprimem novos sentidos e significados a conceitos sociais dos sujeitos que podem impactar em novas concepções nos vários âmbitos de vivências e formação, dentre eles a educação.

Nesse prisma, conforme Arruda (2011), as tecnologias digitais, sobretudo, por meio dos jogos, podem redimensionar os processos educacionais, principalmente de História, ao possibilitar o desenvolvimento de estratégias de aprendizagem, pois 
o jovem "trava contato com aprendizagens de raciocínios e de ideias históricas que são fundamentais para a sua compreensão da historiografia, para a sua posição analítica ante o passado" (ARRUDA, 2011, p. 183).

Assim, evidencia-se a necessidade de repensar a formação docente inicial. Para tanto, Gatti (2010) contribui com a discussão acerca da formação docente, presencial e a distância. Pesquisa realizada pela autora revela tradicionalismo na formação docente, balizada em currículos que não dialogam com a realidade social.

Além disso, segundo a autora, outro complicador pauta-se na desvalorização, pelas próprias universidades, tanto pública quanto privada, em relação aos cursos de licenciaturas, fragilizando as formações, pois isso impacta o exercício da prática na Educação Básica.

Nesse contexto, pensar a formação do docente implica em repensar os currículos de formação, pois são frutos de construções sociais, opção cultural e seletiva e denunciam intencionalidades políticas. Assim, Zabalza (2004) afirma que a formação deve servir para qualificar as pessoas, portanto, deve ser impregnada de sentido social.

De acordo com Guimarães (2012, p. 69), a formação é o momento de construir conhecimento a partir de interações com a complexa dimensão cultural e experiências históricas.

Assim, por meio das discussões teóricas realizadas por esses estudiosos, pretende-se desenvolver esta pesquisa.

\section{DISCUSSÕES METODOLÓGICAS}

Método consiste em uma forma de produzir conhecimento. De acordo com Gatti (2010, p. 2), "Método não é algo abstrato. Método é ato vivo, concreto, que se revela nas nossas ações, na nossa organização e no desenvolvimento do trabalho de pesquisa, na maneira como olhamos as coisas do mundo".

Foi realizado levantamento bibliográfico referente ao assunto abordado, haja vista que a fundamentação teórica é essencial para respaldar qualquer produção científica.

Outra opção metodológica consiste em análises indiciárias de dados coletados, por ora, a partir de documentos como os programas de cursos, matrizes 
curriculares e ementários, além das políticas públicas brasileiras que orientam a formação de professores da educação básica, a formação de professores de História e a educação nacional.

De acordo com Ginzburg (1989), O modelo epistemológico indiciário remonta o século XIX e alinha-se às análises qualitativas, sobretudo, às ciências humanas. Segundo o autor, as análises qualitativas, fundamentadas na observação e investigação de detalhes, constituem recursos significativos para o desenvolvimento de pesquisas pela relevância dos dados analisados. Freitas e Ramos (2010, p. 22) reforçam tal afirmativa, ao elucidar que a pesquisa qualitativa pautada na perspectiva histórico-cultural propicia uma compreensão ativa da realidade pesquisada.

Neste sentido, faz-se necessário a análise de dados quantitativos e qualitativos para o desenvolvimento desta pesquisa. É pertinente ainda, desenvolver a abordagem histórico-cultural, na medida em que constitui uma estratégia enriquecedora na produção de conhecimento. Segundo Freitas e Ramos,

o referencial histórico-cultural, que como uma lupa, amplia nosso olhar sobre os diferentes aspectos da realidade, tanto para explicá-la quanto para buscar formas de transformá-la. Em uma abordagem históricocultural, o intuito da pesquisa qualitativa é a compreensão dos sentidos que são construídos e compartilhados por indivíduos socialmente relacionados. Por isso, embora nos ocupemos de diferentes objetos de investigação, nos empenhamos todos na produção e na partilha dos sentidos que deles emergem. (FREITAS; RAMOS, 2010, p.8).

Diante disso, a produção científica de conhecimento se propõe a dialogar com a realidade do objeto pesquisado, sobretudo, em virtude da contribuição a partir da análise de seus significados e sentidos em uma perspectiva transformadora.

\section{FORMAÇÃO DOCENTE NA CONTEMPORANEIDADE}

O professor é um profissional essencial no projeto educacional. Segundo Guimarães,

é o professor que, investido de autoridade acadêmica e institucional, domina um conjunto de saberes, e é por meio do seu trabalho de planejamento e desenvolvimento do processo de ensino e aprendizagem que se realiza a educação escolar. (GUIMARÃES, 2012, p.24).

Portanto, pensar a formação do professor remete discutir o próprio projeto educacional que se delineia para a sociedade brasileira, pois a formação de gerações 
juvenis decorre, primeiramente, do perfil de formação do professor. Ao longo do processo histórico do Brasil, os governos se preocuparam com a educação, embora não esteja entre as prioridades.

A primeira referência legal sobre educação no Brasil remonta a 1827 , delegando às Províncias a responsabilidade sobre a formação de professores, portanto, cada Província formava seus professores de acordo com suas próprias orientações, sem parâmetros nacionais. O Ato Adicional, em 1834, confirmou tal determinação e a formação de professores para a escola primária foi efetuada pelas Escolas Normais. Essa configuração perdurou até 1889 com o advento da República.

Conforme Gatti (2010, p.1356), as Licenciaturas, criadas no Brasil a partir de 1930, priorizavam a formação de docentes para o "secundário", que correspondia às séries finais do ensino fundamental e o médio.

A formação inicial de docentes, desde sua criação, obedecia à regra conhecida como $3+1$, que consiste no estudo das disciplinas específicas do curso, com acréscimo de mais um ano com disciplinas pedagógicas. A Lei $\mathrm{n}^{\circ}$ 9.394/96, no item Título VI, e as Diretrizes Curriculares Nacionais (BRASIL, 1996), estabelecem algumas propostas para formação de docentes e alterações para a educação básica, respectivamente. Todavia as mudanças nos cursos de formação de professores são bem sutis, prevalecendo o formato muito próximo do tradicional, de caráter racional e técnico, pautado na formação por especialidades com algumas orientações pedagógicas que irão auxiliar na prática do ensino (GATTI, 1997, p.55).

Desde a década de 1970, algumas mudanças contribuíram significativamente com as reflexões sobre a formação docente. Em virtude das intensas críticas ao modelo formador racional e tecnicista, novas perspectivas se delinearam para a formação de professores, pautadas na análise de programas de formação, na aproximação entre instituições formadoras e instituições educacionais, o que oportunizou maior conhecimento da prática de ensino. Ainda assim, os programas de formação permanecem distantes da demanda real.

Gatti (2010, p. 153-154), em pesquisas sobre a formação docente nas licenciaturas de Língua Portuguesa, Matemática e Ciências Biológicas, aponta que nos currículos predominam a formação específica em detrimento da formação docente, inclusive falta articulação entre a formação específica e a pedagógica. Identificou que saberes relacionados aos sistemas educacionais e às tecnologias no 
ensino são muito incipientes.

De acordo com Guimarães (2012, p. 118), as mesmas constatações foram identificadas em cursos superiores de licenciatura em História. Isso impacta de forma significativa a construção dos saberes, inclusive, dos saberes e das práticas docentes na educação básica, dimensão pouco considerada nos cursos de licenciaturas.

Nesse sentido, é imprescindível pensar a formação e profissionalização dos professores a partir das mudanças nas instâncias científicas, pedagógicas, técnicas, artísticas, culturais, sociais, que implicam em novas formas de viver, sentir, pensar e agir.

Guimarães acrescenta que:

As novas tecnologias de comunicação, o rápido e diversificado acesso as informações globais, as relações sociais via redes sociais horizontais demandam novas maneiras de educar e ensinar que não são mais tarefas exclusivas dos professores e das escolas. A sociedade multicultural requer o enfrentamento de práticas discriminatórias e preconceituosas, portanto a necessidade de conviver e educar para a diversidade e as diferenças múltiplas. (GUIMARÃES, 2012, p. 113).

Portanto, a formação docente exige contextualização e diálogo contínuo com a demanda social, uma vez que é construída historicamente. Assim, pensar a educação na sociedade contemporânea pressupõe reflexões críticas sobre as TDIC. Lèvy (1996, p.149) afirma que "a força e a velocidade da virtualização contemporânea são tão grandes que exilam as pessoas de seus próprios saberes, expulsam-nas de sua identidade, de sua profissão, de seu país". A virtualização, ainda segundo Lèvy (1996, p. 151), pode ser definida como o movimento inverso da atualização. A fluidez e a ambivalência do conceito de identidade, tão bem abordado por Bauman (2005), compõem o contexto em que estamos inseridos.

Nesse sentido, em acordo com Arroyo (2004), é dever dos professores conhecer os educandos reais com suas trajetórias e seus tempos. Nessa perspectiva, torna-se imprescindível voltar o olhar para a formação do professor de História, foco desta pesquisa, uma vez que a disciplina é fundamental para a compreensão dos processos e dos sujeitos históricos, o desvendamento das relações que se estabelecem entre os grupos humanos em diferentes tempos e espaços.

Para que o docente de História possa estabelecer diálogos, acerca das TIC, com os sujeitos históricos, sobretudo em ambiente escolar, e que sejam consistentes e críticos, pressupõe-se que a sua formação acadêmica tenha contemplado aspectos 
para subsidiar tais diálogos. A formação não se encerra nos círculos acadêmicos de graduação, pois a formação continuada é essencial para o exercício profissional.

Nessa perspectiva, Nóvoa (1992, p.70) acrescenta que "estar em formação implica um investimento pessoal, livre e criativo sobre os percursos e os projetos próprios, com vista à construção de uma identidade pessoal, que é também uma identidade profissional". Zabalza concorda com a ideia e acresce:

A formação, assim como os demais processos de intervenção pedagógica, faz parte do que Foucault denominava a "tecnologia do Eu", ou seja, os processos deliberados que visam influenciar, direta ou indiretamente, as pessoas no que tange ao processo de construir a si mesmas. A qualidade dessa influência vem condicionada tanto pelo conteúdo da intervenção formativa como pela forma como esse processo ocorre. (ZABALZA, 2004, p.39).

Assim, diante da temporalidade em que vivemos e do impacto desencadeado pelas TDIC, é inviável não se incorporar análises críticas sobre as TDIC ao processo de formação inicial, tanto por meio da matriz curricular quanto no desenvolvimento dos cursos.

De acordo com Lévy (1998. p. 17), vivemos no ciberespaço, definido como "um conjunto de técnicas, materiais e intelectuais, de práticas, de atitudes, de modos de pensamentos e de valores que se desenvolvem conjuntamente na rede". Dessa forma, viver no ciberespaço implica em peculiaridades específicas que possibilitem a interação crítica nessa sociedade do conhecimento e que ultrapassam o uso instrumental das tecnologias digitais. Nesse viés, a própria LDB 9394/96 discorre sobre a necessidade de propiciar a compreensão da tecnologia na educação básica (Art. 32) e promover a formação tecnológica em todas as modalidades de ensino, com intuito no exercício pleno da cidadania, aqui compreendida como pertencimento de um indivíduo a uma comunidade politicamente articulada, um país, e que lhe atribui um conjunto de direitos e obrigações nos âmbito político, social e civil, sob vigência de uma constituição (CARVALHO, 2001, p. 213).

As propostas de mudanças na educação, apontadas por algumas políticas públicas, perpassam quase exclusivamente pela inclusão de máquinas e equipamentos nas escolas e não abordam suas implicações. O atual Plano Nacional da Educação, enquanto política pública de educação, também comprova a emergência referente às TDIC ao mencioná-las em várias metas, inclusive com ênfase na EAD. Porém, de 
acordo com Arruda,

Chama a atenção a ausência de discussões acerca das mudanças na formação inicial de professores não só para o uso, mas para a problematização das TDIC em suas vidas e na de seus alunos. Ainda que sob um olhar determinista, é observada a necessidade de mudança na escola para incorporar novos saberes acerca das TDIC, mas nada é dito sobre estas discussões serem realizadas ao longo dos cursos de licenciatura, restando, após a realização destes cursos, a realização de cursos de "capacitação" de curta duração com o objetivo de aprender a utilizar um software que, no contexto de substituição tecnológica intensiva, provavelmente terá deixado de existir em poucos anos. (ARRUDA, 2013, p.11).

Nesse sentido, de acordo com Moura (2009, p. 08) justifica-se pesquisar a formação de professores de História na perspectiva problematizadora das TDIC, haja vista que a sociedade contemporânea tem vivenciado transformações consideráveis em função da globalização, principalmente por meio das TDIC, de forma que muitos dados são difundidos e devem ser transformados em conhecimentos, isso é feito pelas inferências do professor e do sistema educacional.

Outra abordagem interessante é apontada por Bittencourt (2009, p. 108), ao reafirmar as influências das modernas formas de comunicação, assim como as mudanças culturais provocadas pelos meios audiovisuais e computadores, que colaboram para a formação de sujeitos com novas habilidades e diferentes capacidades de entender o mundo. Ressalta a importância de desfazer-se dos preconceitos para compreender as novas configurações sociais e dialogar com os alunos. Enfatiza ainda que tal situação seja um desafio para os professores, que não devem manter-se ingênuos perante o entendimento do papel das tecnologias na cultura contemporânea enquanto difusoras de informações e o modo como tais informações se integram na configuração do conhecimento escolar.

É importante salientar que essa perspectiva se torna ainda mais crítica com relação à Educação a Distância $(\mathrm{EAD})$, pois a expansão dessa modalidade de ensino como alternativa para a formação de professores ocorre de forma, muitas vezes, precária, além de contribuir com a fragilidade das relações de trabalho, a formação à distância, por meio das TDIC, exige novas práticas e metodologias pedagógicas, bem como discussões e ações sobre a formação e a carreira docente. A EAD redimensiona e altera as concepções de temporalidade e espacialidade, permitindo transpor empecilhos que dificultam o acesso a educação e representa uma forma de 
democratização e efetivação dos direitos à educação.

Portanto,

essa

forma de ensinar propicia novas compreensões do conceito de espaço, tempo, preceitos pedagógicos, aprendizagem e comunicação nos ambientes virtuais, que devem ser discutidos e incorporados criticamente no processo de formação do docente em História nessa modalidade de ensino.

As tecnologias digitais são precursoras de transformações objetivas e subjetivas na vida das pessoas, inclusive na forma de aprender. Segundo Vygotsky (1998), o aprendizado das crianças começa muito antes delas frequentarem a escola. Qualquer situação de aprendizado com a qual se defronta na escola tem sempre uma história prévia. A diferença entre o ensino antes e depois da escola concentra-se na sistematização da instituição de forma que o desenvolvimento ocorra em dois níveis distintos: o real e o potencial.

Diante do exposto, exige-se mais competência e habilidade do professor para conduzir o processo de aprendizagem, conforme afirma Fonseca:

\footnotetext{
Dos historiadores espera-se que conheçam bem a historiografia, os pressupostos teórico-metodológicos que orientam o seu trabalho, as técnicas de investigação, os procedimentos para o tratamento das fontes de pesquisa. Além de tudo isso, daqueles que são também professores de História, espera-se que conheçam os conteúdos, as práticas pedagógicas e os procedimentos didáticos. (FONSECA, 2003, p. 7).
}

Espera-se ainda que sejam sedimentados os pressupostos para a compreensão crítica da sociedade em que vivemos, e cabe à escola e ao professor essa destreza de criticidade e problematização no que tange às transformações advindas das tecnologias de informação e comunicação.

Portanto, há necessidade real em considerar as novas estratégias comunicacionais e de aprendizagem, caso contrário os processos tradicionais de ensino correm o risco de superação ou mesmo abandono por parte dos alunos em função deles próprios dominarem e usarem outras estratégias de aprendizagem (ARRUDA, 2011, p. 85).

Enfim, orienta-se o professor de História a desenvolver e propiciar a aquisição e construção do conhecimento histórico, lançando mão das TDIC, tão atrativas e interessantes, e, sobretudo, com apropriações conscientes e fundamentadas metodologicamente a partir de possibilidades viabilizadas por essas tecnologias. 


\section{CONCLUSÃO}

Analisar a educação, em todos os seus parâmetros, na contemporaneidade, requer pensá-la em seus mais diferentes aspectos, incluindo aí a questão tecnológica. Sabemos o quanto as tecnologias têm influenciado as relações humanas que se estabelecem nos diversos setores de nossa sociedade e, ao mesmo tempo, concordamos também com a ideia de que tais tecnologias e, mais especificamente, seus usos não são destituídos de características culturais e intencionalidades políticopedagógicas. Portanto, a tecnologia enquanto materialização das relações sociais e humanas não possui caráter neutro e tampouco é indissociável das peculiaridades que regem nossa sociedade, particularmente a capitalista, que hoje, afinal, é praticamente hegemônica.

Partindo desse pressuposto e inserindo a educação, em todos os seus níveis, como parte integrante da organização social, compreendemos que o uso das tecnologias, em seus mais diversos aspectos, se faz necessário de forma efetiva na prática docente dos professores de História. A análise bibliográfica nos remete a uma questão que é o cerne da discussão sobre o uso e consequências de tais tecnologias na educação. Elas não devem ser consideradas resolução para todos os problemas que enfrentamos hoje, no cenário educacional brasileiro. Porém, experiências históricas demonstram o quanto elas podem ser aliadas em um processo de ensino e aprendizagem crítico, calcado em valores como a fraternidade, a solidariedade, a construção coletiva de ideias, de projetos e de outras e novas relações sociais, que sejam justas e igualitárias que podem ser reais e de grande interesse dos jovens estudantes.

\section{REFERÊNCIAS}

ALONSO, Kátia Morosov. Tecnologias da informação e comunicação e formação de professores: sobre rede e escola. Educação e Sociedade, Campinas, v. 29, n. 104, esp. p. 747-768, 2008. Disponível em: $<$ http://www.cedes.unicamp.br $>$ Acesso em: 07 jul. 2016.

ARROYO, Miguel G. Imagens quebradas: trajetórias e tempos de alunos e mestres. Petrópolis: Vozes, 2004. 
ARRUDA, Eucídio Pimenta. Tecnologias da informação e comunicação no contexto das práticas e do trabalho docente universitário. Educação Temática Digital, Campinas, v. 15, n. 2, p.264-280, maio./ago. 2013.

ARRUDA, Eucídio Pimenta. Aprendizagens e jogos digitais. Campinas:Alínea, 2011

BAUMAN, Zygmunt. Identidade: entrevista a Benedetto Vecchi. Tradução de Carlos Alberto Medeiros. Rio de Janeiro: Zahar, 2005.

BITTENCOURT, Circe Maria Fernandes. Ensino de história: fundamentos e métodos. São Paulo: Cortez, 2009

BRASIL. Lei no 9.394, de 20 de dezembro de 1996. Estabelece as Diretrizes e Bases da Educação Nacional. Brasília: Casa Civil, 1996. Diário Oficial da União, Brasília, 23 dez. 1996. Disponível em:

$<$ http://www.planalto.gov.br/ccivil_03/Leis/L9394.htm> Acesso em: 10 jul. 2016.

CARVALHO, José Murilo. Cidadania no Brasil: o longo caminho. Rio de Janeiro: Civilização Brasileira, 2001. p. 219-290.

CASTELLS, Manuel. A sociedade em rede. São Paulo: Paz e Terra, 1999.

COLL, César; MONEREO, Carles. Psicologia da educação virtual: aprender e ensinar com as tecnologias da informação e da comunicação. Porto Alegre: Artmed, 2010 .

DANTAS, Marcos. Internet e geração de valor no capitalismo espetacular. In: TAVARES, Rosilene Horta; GOMES, Suzana dos Santos (Org.). Sociedade, educação e redes: desafios à formação crítica. Araraquara, São Paulo: Junqueira \& Marin, 2014. p.79-124.

FONSECA, Selva Guimarães. Caminhos da história ensinada. Campinas: Papirus, 1993.

FONSECA, Thais Nívia de Lima. História e ensino de história. Belo Horizonte: Autêntica, 2003.

FREITAS, Maria Teresa de Assunção; RAMOS, Bruna Sola (Org.). Fazer pesquisa na abordagem histórico-cultural: metodologias em construção. Juiz de Fora: Ed. UFJF, 2010. (Caminhos da pesquisa educacional.

GATTI, Bernadete A. Formação de professores no Brasil: características e problemas. Educação e Sociedade, Campinas, v. 31, n. 113, p. 1355-1379, out./dez. 2010.

GATTI, Bernadete A. Formação de professores e carreira: problemas e movimentos de renovação. Campinas - SP: Autores Associados, 1997 (Coleção formação de professores).

GIDDENS, Anthony. As consequências da modernidade. Tradução de Raul Fiker. São Paulo: UNESP, 1991. 
GINZBURG, Carlo. Mitos, emblemas e sinais: morfologia e história. Tradução de Federico Carotti. São Paulo: Companhia das Letras, 1989. p 143-180.

GUIMARÃES, Selva. Didática e prática de ensino de história: experiências, reflexões e aprendizagens. 13. ed. rev. e ampl. Campinas, SP: Papirus, 2012. (Coleção Magistério: Formação e Trabalho Pedagógico)

KENSKI, Vani Moreira. Das salas de aula aos ambientes virtuais de aprendizagem. [S. 1.]: ABEB, 2005. Disponível em: $<$ http//www.abed.org.br/congresso2005/por/pdf/030tcc5> Acesso em: 08 jul. 2016.

LÈVY, Pierre. O que é virtual? Tradução de Paulo Neves. São Paulo: Ed. 34, 1996.

LÈVY, Pierre. A máquina universo. Porto Alegre: ArtMed, 1998.

MOURA, Mary Jones Ferreira de. O Ensino de História e as novas tecnologias: da reflexão à ação pedagógica. In: SIMPÓSIO NACIONAL DE HISTÓRIA, 25., 2009, Fortaleza, CE). Anais... Fortaleza, CE: ANPUH, 2009. Disponível em: $<$ http://anpuh.org/anais/?p=19378>_Acesso em: 6 jul. 2016.

NÓVOA, Antonio. Vida de professores. Porto: Porto Ed. 1992.

PINTO, Álvaro Vieira. O conceito de tecnologia. Rio de Janeiro: Contraponto, 2005. v.1.

TAVARES, Rosilene Horta; GOMES, Suzana dos Santos (Org.). Sociedade, educação e redes: desafios à formação crítica. Araraquara, SP: Junqueira \& Marin, 2014.

VYGOTSKY, L. S. A formação social da mente. São Paulo: Martins Fontes, 1998.

ZABALZA, Miguel A. O ensino universitário: seu cenário e seus protagonistas. Tradução de Ernani Rosa. Porto Alegre: Artmed, 2004. 